
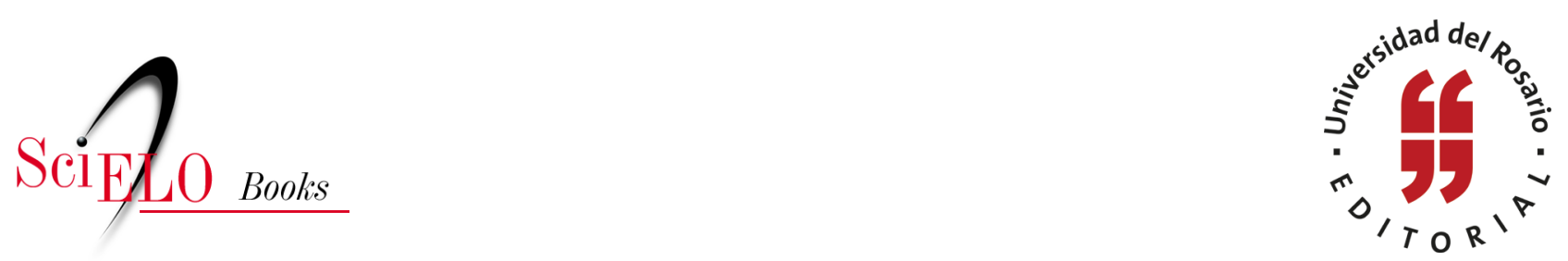

\title{
25. Sus brazos gruesos desnudos sobre el muro
}

\author{
César Augusto Tapias Hernández
}

TAPIAS HERNÁNDEZ, C.A. Sus brazos gruesos desnudos sobre el muro. In: Historias de familia: Etnografía delirante sobre el amor, la violencia y las drogas [online]. Bogotá: Editorial Universidad del Rosario, 2014, pp. 109-114. Textos de ciencias humanas collection. ISBN: 978-958-738-543-4. https://doi.org/10.7476/9789587385434.0026.

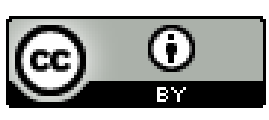

All the contents of this work, except where otherwise noted, is licensed under a Creative Commons Attribution 4.0 $\underline{\text { International license. }}$

Todo o conteúdo deste trabalho, exceto quando houver ressalva, é publicado sob a licença Creative Commons Atribição 4.0.

Todo el contenido de esta obra, excepto donde se indique lo contrario, está bajo licencia de la licencia Creative Commons Reconocimento 4.0. 


\title{
25. Sus brazos gruesos desnudos sobre el muro
}

\author{
Qué bestia fui, recuerdo. Pero recuerdo que me dijo: \\ "No te preocupes. Ya estoy acostumbrado. \\ Creo que se le nublaron los ojos, y a mí, peor". \\ Evelio José Rosero, Cuchilla
}

Como si el tiempo se resistiera a pasar, el láser del equipo de sonido del primo Alberto no deja avanzar normalmente los $\mathrm{CD}$ : se devuelven los temas musicales antes de terminar. No terminan porque se devuelven sobre sus notas y todo se hace una constante repetidera de un solo acorde, algo que no se hace molesto sino hasta después de un rato cuando nos damos cuenta de que Ray Barretto no para de tocar el mismo tumbao sobre las congas...

—Hummmm... No se cansa este Barretto. ¡Qué monstruo! — dice el primo.

El primo Alberto es un tipo gordo-gordo, pero según parece solo desde algunos años para acá. Aun cuando yo siempre lo he visto así, gordo-gordo y barrigón, como si se tratara de un Buda. A veces tiene la desfachatez de andar por ahí sin camisa con su inmensa barriga —el mundo - y el porvenir al aire... y se pilla uno que su cuerpo es proporcional al tamaño de brazos y manos gruesotas. El barrigón por lo regular viste de jeans anchos caídos atrás, camisas también anchas, usando botas y casi siempre motilado muy tuso.

-Pero antes de casarme yo más bien era flaco... Y también muy loco. Finalmente fue necesario organizarme, porque corría el peligro de no ser nada si seguía como iba...

Y es que el primo se la pasaba jugando dados, bebiendo y peleando por allá en Bello cuando apenas era un pelao, y peleaba tanto que a lo último tuvo que andar enfierrao y lleno de puntas. Según parece, eran muchas culebras las que tenía... Al final se tuvo que ir de la casa y fue a dar a El Pedregal, adonde su tío Fonso, es decir, 
mi abuelo. Yo jamás llegué a considerar realmente necesario, benéfico para uno mismo y su "calidad de vida", formar un hogar (y aún lo pienso). Si bien es cierto que no somos islas, como individuos también valemos. El primo dice tener siempre la sabiduría de escucharse en los momentos cruciales de la vida:

- Se trata de hallar el yo interior.

-Y ese "yo" le dijo un día que mejor se casara, de lo contrario...

— Nada de nada con esta vida de loco.

Esa sabiduría le permitió entender en su debido momento que lo mejor era estudiar; pero cuando terminó quinto de primaria, su papá le salió con que... ¡Ya no más!

- Mire a ver qué hace, usted ya está muy grande...

Alberto había ahorrado unos pesos de cuando trabajaba barequeando en Segovia por vacaciones de la escuela, para con esa plata ayudarle al cucho a pagar su estudio... Pero nada de nada tampoco... Pelaíto se fue de la casa y pelaíto también se casó:

-Yo tenía dieciséis años; Lucrecia, mi novia, era mayor que yo como por cuatro años... Doña Carlota, la mamá de ella, me dio el aire de la casa y ahí construí...

Y es que en El Pedregal no solo se salvó Alberto de las culebras callejeras, y de tanto tropel, sino que conoció a Lucrecia mientras sorteaba otra clase de broncas: las de la casa de mi abuelo. Escapado de la calle y su rudeza, Alberto terminó correteando al tío $\mathrm{H}$, lo agarraba y se lo llevaba al papito Fonso, que lo cascaba con un alambre... Dice Alberto que mi tío era tan grosero que una vez hasta le tiró la comida en la cara a la mamita Gélica.

-Ese día acompañé a su mamita a poner el denuncio allá en los Carabineros... al día siguiente lo encanaron en la correccional de menores...

Sin embargo, aun cuando el primo parecía neutral ante los conflictos de la familia que lo acogió, terminó empeliculao cuando la Melia apareció casada: que era un alcahueta, le decía mi abuela al primo, y él sin saber nada de nada...

-Melia sí me había dicho de su idea de casarse; incluso me pidió que fuera el padrino junto con Lucrecia, pero nunca supe más hasta cuando dijo que ya se había casado... Y fue a mí a quien se la montaron.

A lo bien, pienso que el primo podría resumir algunas anécdotas de la casa de los abuelos, pero se pilla uno que después esas mismas anécdotas lo dejaron mal parado. A lo mejor de ahí, de la experiencia, sacó el primo Alberto tan mala cara:

- Recién casado su papá, por ejemplo. Él me contó de una vuelta con otra vieja por ahí. En la casa como que escucharon y quién sabe qué pensaron; pero eso 
se volvió una calentura tremenda, todas aleteadas, la Melia sobre todo, me cogían a preguntarme sobre qué era lo que me decía Alberto y yo que no decía nada. Hasta su mamá se enojó conmigo. Yo a la final siempre reuní buenos argumentos para ser la mala compañía... La puta del paseo.

Un día apareció $\mathrm{H}$ como con ganas de cobrarle al primo las sapeadas y las carreras para cogerlo y llevarlo adonde el abuelo. Entonces lo llamó por el balcón y le fue diciendo:

—Alberto, Alberto, sacá lo más grande que tengas y vamos a matarnos...

Y Alberto sacó un machete ni el hijueputa de grande... Y casi mata al pobre $\mathrm{H}$, según cuenta él, que le abrió la cabeza y a punto estuvo de botarle un brazo... En ese brazo lleva el tío $\mathrm{H}$ una de las cicatrices más grandes entre las muchas que el callejeo le ha dejado por todo el cuerpo... Como la barriga del primo Alberto, yo creo que las cicatrices de mi tío $\mathrm{H}$ son como una página del libro abierto que ha sido su vida.

Pasado el tiempo y todavía pelao, el primo Alberto se pasó a vivir enseguida de los abuelos, donde Lucre, en el aire que le dio doña Carlota y desde ahí a batallar con nuevas broncas. Gracias a un hermano de Lucre, Alberto volvió a estudiar: se metió al Sena, a Mecánica y Soldadura. Camelló y se hizo a una casa prefabricada de la que hoy, dice él, lo quieren sacar... Después de catorce años, las cosas no han salido tan bien: el primo ha pasado por dos grandes crisis que le han significado deshacerse de las cosas más queridas y, obviamente, el amor también sufre sus quebrantos cuando no hay plata... Alberto dice que después de casado, con casa y dos hijas, lo demás era ganancia; sin embargo, esas ganancias se han ido gastando para poder seguir batallando, o sea que las ganancias esas vienen a ser como una especie de reserva para los tiempos malos...

Alberto tuvo que vender su colección de salsa. Unos ochocientos álbumes en pasta fina y grabaciones originales. Salió también de la herramienta, el soldador... La última mala racha duró como dieciocho meses. Solo ahí vendió más de cien de sus CD..., y me da una tristeza que a mí mismo no me cabe en el pecho: sí, la familia puede salvarlo a uno, bien, pero hay que tener en cuenta que eso se voltea y termina uno salvando a la familia en detrimento de uno. Sacrificios que llaman, actos de amor... pero bueno, Alberto dice que todavía le queda algo de esa música dura - cantadora de verdades-golpeadora de almas-azaradora de mentes- callejera, música que a la final algún día espera volver a conseguir..

-Es que cuando las cosas están mal, hay que pegarse de lo que sea que tenga, de lo que sea que tenga... 
En esas andanzas callejeras que el primo aún continúa haciendo, farras que terminan comiendo morcilla en Balalaika a las tres de la mañana, el primo dice haber probado de todo y después de los años solo quedarse con el guaro. La bareta y el perico son solo fórmulas de escape a la realidad, cosas que ya no le interesan al primo, porque siempre es mejor meterle el pecho a todo... O si no, ¿para qué ese cuerpo de Buda gigante?

Ahora, con un nuevo empleo y esperando se enmienden los errores que con él se han cometido, espera arrancar de nuevo. De hecho, cree estarlo haciendo de a poco, entonces con la tranquilidad que lo caracteriza, el gordo-gordo se recuesta en el balcón de su casa a fumarse un cigarro mientras ve pasar a cada quien con sus preocupaciones y sus penas... Sus brazos gruesos descansan desnudos sobre el muro que recibe todo su enorme peso; justo ahí junto a la puerta de su casa prefabricada levantada sobre una terraza por donde se escapan los sonidos bulliciosos de la salsa que aún le queda y que pone a sonar a cualquier hora: un domingo en la madrugada, por ejemplo, aun a pesar de las vecinas, de la suegra y de las hijas...

Y borracho del desencanto que a veces lo habita a uno, o de la alegría que le otorgan unos tragos, el primo Alberto evoca la canción del hombre que salió de casa a las cuatro de la mañana directo al Pueblo de Morón, con un tabaco en la boca, pero que a Morón nunca llegó...

Así mismo, con el tiempo, como el hombre de la canción, Alberto se fue a algún lugar... dejando sola a Lucrecia y dos hijas adolescentes.

$\infty \infty \infty$

En el artículo "Cambio social, familia patriarcal y emancipación femenina en Colombia”, la profesora Virginia Gutiérrez de Pineda dice que constituye un lugar común asegurar que las instituciones y la cultura colombiana han cambiado aceleradamente desde la mitad del siglo pasado, y no se puede pronosticar fácilmente su estancamiento o dinámica. Conviene, sin embargo, focalizar áreas de transformación para ver aciertos y desaciertos que proyectan en la vida social esas transformaciones. Se me ocurre que en el área de las interacciones que he venido describiendo etnográficamente puede verse que si la famulus esclaviza, o prepara para la opresión, un acierto de sus transformaciones - léase también crisis - tal vez sea la independencia, más que económica, ética por lo personal, también política por el poder que involucra, mas... algo espiritual, si se quiere psíquico, que nos hace más conscientes de las consecuencias de nuestra acción: pequeñas luchas de 
emancipación ganadas, que brindan nuevos elementos para capacidad de maniobra, de acción, de agencia (Giddens, 1986), vital para (existir de forma cada vez más libre) la construcción de lo social. Ya sea por la fuga del padre, o de la madre... de la pareja; por su muerte violenta o natural... o por el deslizamiento de los sujetos entre roles que no asumen so pena de perder autoridad... poder... aprendemos a saber que estamos solos en medio de mucha gente.

Cuatro funciones familiares son, sin lugar a dudas, las de mayor visibilidad durante estos cambios: la económica, la sexo-reproductiva, la de germinación gratificante y la de socialización y crianza. Es necesario reiterar que estas transformaciones se encuentran íntimamente relacionadas con los cambios institucionales. La transformación de la función económica familiar, por ejemplo, su reasignación como rol a otro actor de la familia es, sin lugar a dudas, la que mayores repercusiones produce sobre las demás funciones, la estructura familiar y la relación de los géneros. No es una novedad entre nosotros el trabajo productivo de la mujer casada, fuera de las tareas relativas a la reproducción adscritas a su estatus y género, que han intervenido desde siempre en su quehacer.

La mujer fue parte del peonaje agrícola y en la etapa artesanal mantuvo desarrollos, bien como unidades productivas o como ayudantes familiares sin remuneración bajo el comando del marido, condición que le restaba figuración a su aporte, para después desempeñar la jefatura económica en procura del sustento de su prole, o en la viudez, en el madresolterismo o en el abandono marital.

También debe considerarse la profesionalización, el cambio cultural ante el trabajo de la mujer casada y la planificación familiar, como componentes que redujeron sensiblemente el número de hijos por mujer en edad fértil, junto al desplazamiento de la crianza hacia instituciones que le han permitido a la mujer permanecer en el trabajo fuera del hogar. Si por tradición cultural la madre está llamada a asumir la carga filial, y en las crisis de la familia esto demuestra la capacidad de jefatura económica de la mujer urbana, separada o madre soltera, es necesario comprobar si como consecuencia de la coproveeduría de la madre el padre actual se ha hecho irresponsable o es que, ahora, ante la denuncia femenina, se evidencia un problema que en el pasado permanecía encubierto.

También vale la pena preguntar y responder con investigaciones si el cambio operado en la función que analizamos estimula negativamente el desempeño del hombre en su papel de providente. Hoy parece que, a semejanza de la mujer patriarcal, el padre asume el estatus de mantenido, y que valiéndose de su poder tradicional, está tomando ventaja personal del aporte de su pareja para eludir su deber 
progenitural. Veremos a la mujer que huye a la sumisión a los hijos, al marido, y al hombre, eludido del deber...

Tales escenarios etnográficos ayudan a ver cómo esa transformación de la función económica, que promueve la coparticipación femenina, es fuente de duros conflictos, pues hacen referencia a algo más que el descargo que el hombre hace de su obligación de cooperación y que deja sola a la mujer en la cobertura de la función. Dos modalidades: la ya citada de cabeza económica femenina manifiesta y la forma encubierta tanto cuando la pareja no ha roto su convivencia como cuando la ha abandonado. 